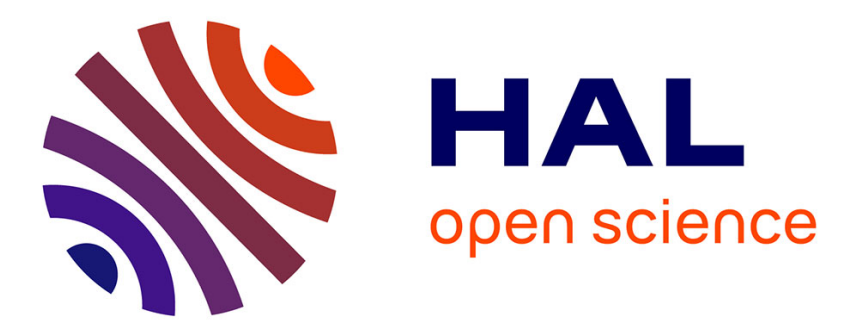

\title{
Pragati - A Mobile Based Virtual Reality (VR) Platform to Train and Educate Community Health Workers
}

Keyur Sorathia, Kshipra Sharma, Shimmila Bhowmick, Preetham Kamidi

\section{To cite this version:}

Keyur Sorathia, Kshipra Sharma, Shimmila Bhowmick, Preetham Kamidi. Pragati - A Mobile Based Virtual Reality (VR) Platform to Train and Educate Community Health Workers. 16th IFIP Conference on Human-Computer Interaction (INTERACT), Sep 2017, Bombay, India. pp.459-463, 10.1007/978-3-319-68059-0_51. hal-01679781

\section{HAL Id: hal-01679781 \\ https://hal.inria.fr/hal-01679781}

Submitted on 10 Jan 2018

HAL is a multi-disciplinary open access archive for the deposit and dissemination of scientific research documents, whether they are published or not. The documents may come from teaching and research institutions in France or abroad, or from public or private research centers.
L'archive ouverte pluridisciplinaire HAL, est destinée au dépôt et à la diffusion de documents scientifiques de niveau recherche, publiés ou non, émanant des établissements d'enseignement et de recherche français ou étrangers, des laboratoires publics ou privés. 


\title{
Pragati - A Mobile Based Virtual Reality (VR) Platform to Train and Educate Community Health Workers
}

\author{
Keyur Sorathia, Kshipra Sharma, Shimmila Bhowmick, Preetham Kamidi \\ Indian Institute of Technology, Guwahati
}

\begin{abstract}
Accredited Social Health Activists (ASHAs) are essential link to healthy communities in resource-constrained environments. However, they are insufficiently trained to solve community health challenges. In this paper, we present Pragati - a mobile-based Virtual Reality (VR) platform to train and educate ASHAs in rural Assam, India. Mobile based VR platform was chosen due to its ability to increase focus, attention and learnability among users. We developed 3 modules on maternal and child healthcare. Modules were presented via audio-visual interface in local Assamesse language. This paper presents the design of Pragati, user interactions, technology implementations and future directions of our study.
\end{abstract}

Keywords: ICT in Social Development - Interaction Design for Developing Regions, Technology in Healthcare, Virtual Reality, Medical Training, Community Health Workers

\section{Introduction}

ASHAs act as a primary tool against the menace of child malnourishment, infant mortality and aide in curbing preventable diseases in rural communities in India specially in rural areas [6,7]. Despite being an essential link to quality healthcare, they are often ignored. Their health education and skillsets are often limited due to delayed due to insufficient training, the use of non-engaging methods, outdated health information and little or no feedback on their training and education $[6,8]$. This presents an opportunity to design solutions that timely train ASHAs through engaging methods in order to improve community healthcare in developing regions.

Penetration of Information Communication Technology (ICT) tools, especially mobile phones have increased accessibility in remote regions and provided with better opportunities for digital services [1]. They possess benefits of easy outreach and information access, repetitive learning [4], cost-effective information sharing [3] and communicating sensitive health information effectively [2]. Moreover, mobile phone interventions supported through VR interfaces provide rich, immersive, and engaging educational context supporting experential learning [5], which results in increased learnability, attention and memorability among targeted users [9]. In this paper, we present the design of Pragati- a mobile based VR interface targeted towards training 
ASHAs in the state of Assam in India. This is followed by details of technology implementation and future directions of our study.

\section{Design of VR Interface}

Pragati is a mobile phone based VR interface aimed at training and educating ASHAs in Assam, India. We created a 360 degree virtual environment of a traditional Assamese home where the modules are demonstrated. Audio-visual animations related to maternal and child healthcare were created in local Assamese language. We designed two personas 'ASHA baidew (sister)' - who moderated and guided users through each module and 'Meera' - who enacts as the woman going through pregnancy to increase familiarity and acceptance among users. Figure 1 (a), (b) \& (c) showcases virtual environment, ASHA baidew and Meera respectively. Information was presented in a mobile phone mounted on a Google cardboard. This is due to its lower cost and potential scalability among targeted user group.
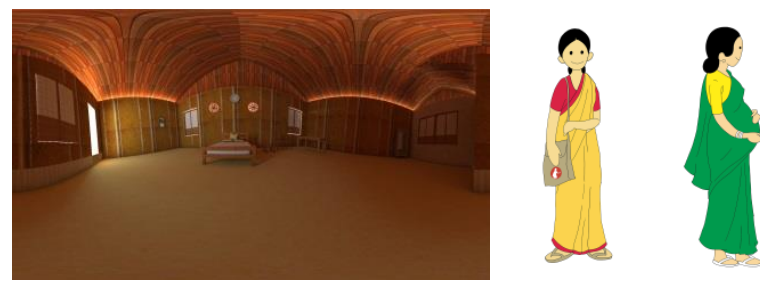

Fig. 1. (a) Virtual (360 degree) environment of Assamese home (b) persona of ASHA baidew and (c) persona of Meera

Each information module is narrated in 5 main sections - (i) introduction of the module by ASHA baidew (ii) narration of healthcare content (iii) intermediate interactive task/questions (iv) summary of the module and (v) questions relevant to the module. Figure 2 showcases the module framework for Pragati.

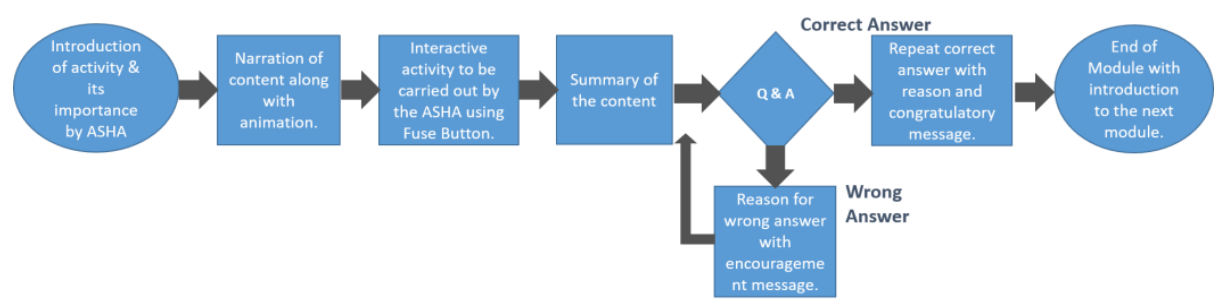

Fig. 2. Framework structure of information modules of Pragati

We designed following 3 modules on the maternal and child health. We chose the modules based on high priority training subjects in the ASHA training curriculum. 


\section{Module 1: Safe delivery}

The module presents the methods of healthy delivery of a pregnant women in a home setting. The role of ASHAs is to assist in performing the delivery activities through recommended steps. It presents 3 stages of delivery and relevant precautions undertaken for safe and healthy delivery.

\section{Module 2: Newborn examination}

The newborn needs to be examined at birth for stillbirth or any other health related precautions by immediate examination after birth. This is performed by observing breathing, limb movement and crying of a newborn. It also recommends carious activities in case of a potential stillbirth.

Module 3: Normal care provision to newborn

This module presents steps for immediate post-partum care for the newborn. Appropriate methods of drying the baby and mantaining the baby's temperature are recommended during this module.

We explain the design of Pragati in 3 sections - (i) design of virtual environment and personas (ii) interactive tasks and activities and (iii) input interactions

\subsection{Design of Virtual Environment \& Persona}

We created virtual simulation of traditional Assamese home environment, a persona of 'ASHA baidew', and a young mother 'Meera' and to increase familiarity of the context among users. Persona of 'ASHA baidew (sister)' imitates a 45 year old Assamese lady with over 10 years of experience as ASHA. The role of ASHA baidew is to introduce each module, indicate the significance, provide tasks and activities and guide the users through each module. Meera imitates a young and first time pregnant woman who enacts various stages of pregnancy and problems that occure during pregnancy.

\subsection{Interactive Tasks, Activities and Questions}

We presented activities and tasks in between each module to increase focus and attention among users. We scripted activities, tasks and intermediate questions into the dialogue during the training sessions. For example, module 3 demands drying and cleaning of a newborn immediately after delivery. An activity of drying the newborn is proposed during the module. The module resumes when the drying and cleaning activity is completed by users. Similarly, a series of questions are asked to users post module description. For example, module 1 demonstrates Meera's womb activity which releases colored fluid during break down of amniotic sac. The color of fuild determines its infectuous stage. A question is asked to users post completion to module - "Which fluid color indicates infection?" The user can choose the answer from choices provided on the interface. Correct answers are appreciated through congratulatory messages where as incorrect answers are supplemented by reasons and given another chance to answer questions. 


\subsection{User Interactions}

We designed Pragati for mobile based VR mounted on a Google cardboard (or similar cheap cardboards) to increase scalability. Hence, our proposed interactions are limited to fuse button mounted on Google cardbaord. Users select the given options by pressing the fuse button multiple times i.e. tap once to choose option one, tap twice to choose option two and tap thrice to choose third option. We presented audio instructions to aide in choosing relevant options. A horizontal menu selection user interface was presented to choose relevant options. The menu selection options were tracked and presented to user irrespective of head position. Figure 3 showcases the horizontal menu user interface proposed in Pragati.

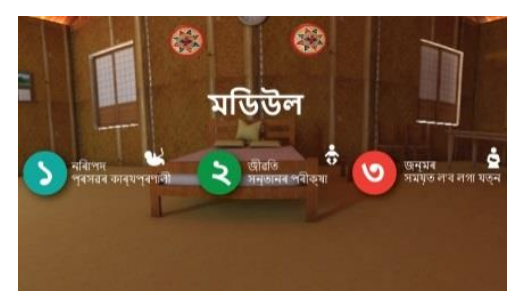

Fig. 3. Proposed horizontal menu user interface for Pragati

\section{Technology Implementation}

Andriod, Unity 3D and Google's VR Software Development ToolKit (SDK) was used to develop Pragati. We used 2D graphics as objects instead of 3D objects based virtual environment using unity skybox in order to make it compatible low end smartphones. This also enabled quick modifications as per our requirements. Each module was further animated using Adobe After effects with specified user interactions at regular intervals. We develop 2.5D environment using parallax-style animation to reduce rendering intensity and memory requirements. Figure 4 shows the schematic diagram of technology implementation of Pragati.

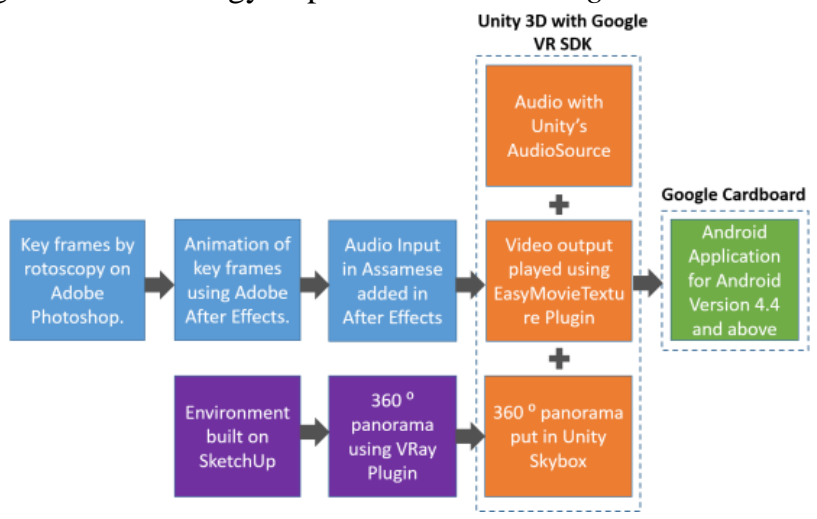

Fig. 4. Schematic diagram of technology implementation of Pragati 


\section{Conclusion and Future Work}

In this paper, we presented Pragati -a mobile phone based VR platform to train and educate ASHAs in Assam, India. Pragati used audio-visual information modules communicated through familiar virtual environment and personas. Interactive tasks, activities and questions were used during and post module sessions to increase attention and focus among users. We developed 3 modules on maternal and child healthcare on home delivery, newborn examination, and newborn care. These modules were interacted through fuse button based input interactions and horizontal menu based user interfaces. We have developed the protoype and field trails are in process to study overall acceptance, engagement and learnability as compared to traditional training methods. We aim at conducting longitudnal studies by incorporating Pragati with traditional training sessions to study the retention rates and learnability and present empirical findings in future. Moreover, we will be using Pragati to conduct a camparative evaluation study to investigate self-efficacy, learnability, engagement and presence across three common information dissimenation platform (a) traditional 2D audio-video module (b) modules presented on mobile phones based VR without head mounted display and (c) module presented on mobile phone based VR with head mounted display.

\section{$5 \quad$ References}

1. Telecom Regulatory Authority of India, Annual Report on Penetration of Mobile phone (2009).

2. Fiore-Silfvast, B., Hartung, C., Iyengar, K., Iyengar, S., Israel-Ballard, K., Perin,N., \& Anderson, R. Mobile video for patient education: the midwives' perspective.In Proceedings of the 3rd ACM Symposium on Computing for Development (p. 2).ACM (2013, January).

3. Kallander, K., Tibenderana, J. K., Akpogheneta, O. J., Strachan, D. L., Hill, Z., ten Asbroek, A. H., \& Meek, S. R. Mobile health (mHealth) approaches and lessons for increased performance and retention of community health workers in low-and middleincome countries: a review. Journal of medical Internet research, 15(1), e17 (2013).

4. Li, J., \& Alem, L. Supporting distributed collaborations between mobile health workers and expert clinicians in home care. In CHI'13 Extended Abstracts on Human Factors in Computing Systems (pp. 493-498). ACM (2013, April).

5. Mantovani, F. (2001). VR learning: Potential and challenges for the use of 3D environments in education and training. In G.Riva \& C. Galimberti (Eds.), Towards cyber psychology:Mind, cognitions and society in the internet age (pp. 207-226). Amsterdam, the Netherlands: IOS Press.

6. Molapo, M., \& Marsden, G. Software support for creating digital health training materials in the held. In Proceedings of the Sixth International Conference on Information and Communication Technologies and Development: Full Papers-Volume1 (pp. 205-214). ACM (2013, December).

7. Molapo, M., \& Marsden, G. Health education in rural communities with locally produced and locally relevant multimedia content. In Proceedings of the 3rd ACM Symposium on Computing for Development (p. 25). ACM (2013, January). 
8. Pakenham-Walsh, N., Priestley,C., and Smith, R. Meeting the Information Needs of Health Workers in Developing Countries. British Medical Journal, 314:90, (1997, January).

9. Youngblut, C. (1998). Educational uses of virtual reality technology.Alexandria, VA: Institute for Defense Analyses.Retrieved from

http://papers.cumincad.org/data/works/att/94ea.content.pdf 